\title{
Current Conceptual Problems of the Russian Agrarian-Industrial Complex Digitalization in the Globalization Content
}

\author{
Volostnov N.S ${ }^{\text {., Lazutina A.L. }}{ }^{\text {, }}$, Klyueva Y.S ${ }^{\text {., }}$ Morovova I.M. ${ }^{\text {, }}$, Nazarova N.E. e , Butchenko V. N. $^{\text {f }}$ \\ a, b, c, d,e Institute of Food Technology and Design' - branch of the state budgetary educational institution of higher professional \\ education 'Nizhny Novgorod State Engineering and Economic University' \\ bizhny Novgorod State Pedagogical University named after Kozma Minin (Minin University) \\ 'Volga State University of Water Transport'
}

Article History: Received: 10 November 2020; Revised 12 January 2021 Accepted: 27 January 2021; Published online: 5 April 2021

\begin{abstract}
The modern global economy is becoming more digital, and at great speed, intensity, and scale. Its international universal 'language' is information technology. Only this 'language' is objectively possible to 'understand', to interact concerning isolated, national reproductions taking place in many states. It is the need for this understanding, as well as for its practical use, that act as the criteria reasons for digitalization of the national economy of Russia as a whole, and its organic component - the agro-industrial complex.

Another reason, is the economic necessity of the above-mentioned phenomenon, which allows receiving, store and transmit information about counterparties, tariffs and make contracts, make fuller use of limited resources, and in the best way satisfy both production and personal needs of various subjects in real-time [1].

The article reveals the content of the modern stage of the Russian agro-industrial complex digitalization in its integrity and specificity
\end{abstract}

Keywords: digitalization, IT sector; traditional economics; national economy; agro-industrial complex; global economy

\section{Introduction}

Nowadays, both in journalism and in scientific literature, there is a huge flow of publications devoted to the digitalization of economic processes, phenomena, relations, objects, and at various levels from the individual, families and other institutions of humanity, now divided into separate states or unions of states.

Not to mention the level and quality of these publications, it should be emphasized that their 'fan' is quite variegated in some, unconditional, unrestrained enthusiasm is demonstrated on this score, since, supposedly, the latter will help people, like a panacea, to successfully and quickly resolve all their problems; in others, various potential threats are seen in it, in particular, that it can make the majority of workers unnecessary, since they will be replaced by robots, artificial intelligence, which, on this basis, paradoxically, will 'impoverish' the content of their work; still others see it as an unlawful, inhuman strengthening of the functional role of the state a 'big brother' capable of a total, repressive character, the formation and control of the behavior of the personality of each member of society; still others consider it from a conspiratorial position on a global scale, proceeding from an alleged selfish conspiracy of the most financially powerful family plans, oligarchic structures; fifth, when studying this phenomenon, proceed from theological assessments of the apocalyptic plan, considering it as a sad fatal inevitability, as a harbinger of 'the end of history'.

What is this phenomenon from a scientific point of view, including in the sphere of the agro-industrial complex of the national economy of Russia?

\section{Materials and methods}

Before answering this question, it should be noted that the digitalization of the national economy of Russia is currently an organic component of global digitalization in almost all spheres of human existence [6]. Further, representing the process of formation, functioning, and intensive development, it is comprehensive, contradictory, and often conflicting in nature, associated with a simple and expanded reproduction of the national economy, its subjects, in particular, associated with the current conflicts between the creators of the so-called 'hardware' and 'software', both in civilian industries and in the military and mixed sectors; complication and cheapening of its components (from mobile communications to artificial intelligence; from wired telecommunications to the Internet; from an adding machine to a quantum computer, etc.). 
If we talk about such an important key component of the national economy of Russia as the agro-industrial complex, then its digitalization should be viewed, as it seems, mainly from a pragmatic standpoint, as a digital practice with adequate, systemic, complex, congruent consideration of its cognitive and praxeological features [9]. This means that in this area, being connected, first of all, with living matter (i.e. earth, animals, plants, fish, insects, microorganisms, etc.), it must take into account the need to observe a careful attitude towards itself, which does not allow unreasonable interference in their existence, associated, in particular, with their reproduction, conservation of biodiversity, the transfer of the latter to offspring; with the ensuing scale of the tasks that digitalization must solve, since, as is known, at present in Russia there are millions of heads of cattle, pigs, sheep, goats, poultry, etc., which will require colossal material and financial costs for the implementation of digitalization tasks in this area; the presence of a life cycle in natural systems in animals, in plants; significant impact on the objects of the agro-industrial complex of natural, climatic, landscape factors; the contradictory impact of the policies of developed states in this area as a whole on digitalization in Russia.

Moreover, it is the integrity of the Russian national economy that should be based on this, determine the content and mechanism for the implementation of digitalization of the agro-industrial complex for the country, taking into account the objective laws of the socio-economic development of society in specific historical conditions. [7].

In this sense, we should talk about the agro-industrial complex digitalization:

firstly, a systematic, total, real-time digital support due to internal and external economic phenomena, other processes, for example, in soil plowing, sowing grain, harvesting, transporting it, processing, storing, optimizing the remainder of grain at the mill, at the bakery, on its export supplies and the like. Doing all this is not only quite expensive but also requires a lot of time, involving a large number of specialists in various fields (i.e. mathematicians, programmers, agronomists, plant breeders, veterinarians, livestock specialists, engineers, managers, owners, government agencies, etc.) [2];

secondly, about the known transformation of the current traditional natural, economic, social processes in a modern village, which are conditioned, determined by digital information technologies to make their simple and expanded reproduction more reliable, guaranteed, sustainable, continuous, intensive, and integrative in the content of use both continuous and discrete production technologies based on a systemic, timely, complete, objective reflection, effective use of information in real-time for an interested user (i.e. from a geneticist to a buyer);

and thirdly, the creation, implementation, transportation of qualitatively new economic benefits created on digital technologies and artificial intelligence.

It must be noted that the directions, the scale of implementation, and the use of digital information technologies in the agro-industrial complex of modern Russia reflect the different, both in content and in form, the interests of heterogeneous subjects, varying from the problems of individual consumption, families, and state; and security, and, in the contradictory influence on this process of the diversity of levels of functioning and development of various subjects, i.e. from nano - to mega-levels [8].

Speaking about the effectiveness of this process in the agro-industrial complex of Russia, one should pay attention to the fact that digitalization objectively conditions, generates the following types of them:

- Science integration with the simple and extended reproduction of the national economy processes;

- Genetic engineering of qualitatively new seeds, plants, breeding of new, highly productive animals and microorganisms;

-Use of nature-like technologies, allowing to accelerate biochemical processes, more efficiently, more fully use feed, mineral fertilizers, agricultural raw materials, ensure the safety of the latter, its usefulness, and the complexity of its use [3];

- Creation, replication, and use of highly efficient, 'green' technologies in crop production, animal husbandry, processing industry, etc.;

- Productivity increase of social labor based on the generation, operation, service, and automation of modern agricultural machinery, equipment for the processing industry based on digital information technologies, including artificial intelligence (for example, today this is manifested in the operation of combines without a combine operator, cars without drivers and others) [10];

- Acceleration, simplification, and cheapening of settlements, payments, including through the use of a wider range of monetary, foreign exchange and financial instruments of a national, international nature; a significant reduction in production and non-production and especially transaction costs associated with searching and finding 
information about economic benefits, prices, and tariffs, with monitoring the behavior of various cooperative chains, with obtaining state and municipal services and providing the latter with the information requested by them [5];

- Timely information, both from abroad and from national structures associated with the activities of the agroindustrial complex;

- Creation of new economic benefits, new technologies for processing agricultural raw materials based on the use of artificial intelligence;

- Direct losses reduction of agricultural economic benefits from economic actors of different levels, different localization (national, international) during production, transportation, storage and in wholesale and retail trade, including in connection with criminal structures;

- Saving material and financial resources associated with the scientific regulation of the formation and effective use of resources in the agro-industrial complex (for example, based on digital control of the work of car drivers, which does not allow them to steal fuel, artificially winding up the mileage of vehicles);

- Ensuring a normal reproduction process among agricultural producers, processors (in particular, from the development of projects and plans for sowing certain crops, receiving an order and concluding a contract to receiving finished products, processing them, disposing of waste straw, manure, pulp, etc.);

- Scientifically grounded reduction in the life cycle of certain agrarian and economic benefits (i.e. plants, animals, etc.);

- Optimization of load and intensity of production and other areas related to agriculture like fields, farms, processing enterprises, etc.;

- Complexity increase of agricultural economic benefits (as they say, from horns and hooves of cattle to blood during slaughter);

- Network economy of material and labor resources, associated with the fullest satisfaction of the stated needs and demand due to the systematic use of the world's best production, logistics, and other practices;

- Time constraints like the seasonality of production and consumption of agricultural economic benefits in the global circuit (such as fruits, vegetables, berries, and green crops);

- Obtaining synergistic effects from the integration of production, circulation, lending, service at the local, national, and international levels;

- Speed, reliability, quality, and safety increase of creating normal value (like fair prices and tariffs) for information, material, and other flows.

\section{Results}

The digitalization of the Russian national economy, especially if we talk about the agro-industrial complex, should be emphasized that it has a specific historical, dynamic, and contradictory character (in terms of scale, pace, financial component, staffing, etc.).

Secondly, this process is quite expensive, due to the specifics of the digitalization objects themselves in this area (i.e. huge areas of forests, meadows, fields and the variety of their seasonal state; a large number of various breeds of animals, birds, beneficial insects, etc.; significant influence in this area of natural and climatic conditions, landscapes on the life cycles of biota; the use in this area of space observation expensive complexes and communication).

It is possible and necessary to single out the following fundamental principles of the Russian agro-industrial complex digitalization, functioning, and development:

- humanization (there are only two IT specialists per 10,000 employees in the Russian agro-industrial complex);

-providing a systemic, integrated, ecological and reproductive approach; adequate accounting of its nano-, micro-, meso-, macro-and mega- levels;

- achieving a synthesis of its state regulation and market self-regulation, with the leading role of the state;

- active and productive participation, without the admission of any infringement of national sovereignty of foreign players, from individual programmers, mathematicians to commercial and other structures.

It seems that the success of solving the above problems will undoubtedly be facilitated by: 
- firstly, active creation and effective implementation of domestic digital information systems;

-second, the skillful use of international digital structures of various levels;

-third, effective, productive, and safe participation of national digital actors in various projects abroad (in particular, to gain experience, attract personnel, purchase equipment, etc.). It is known that Stalin J.V., despite the need to preserve state secrets, proceeding from the scientific and practical interests of the atomic physicists of the USSR, allowed them to participate, in various forms, in the corresponding international exchange.

\section{Discussion}

The modern practice of the Russian agro-industrial complex digitalization, especially in the content of the national economy reproduction; the life of the society and state has no national strategy for digital agriculture [16].

The current sectoral project for the digitalization of Russian agriculture is currently available but is rather narrow, especially because it sets its goal in the transformation of agriculture through the introduction of digital technologies and platform solutions, to ensure a technological breakthrough in the agro-industrial complex, to achieve productivity growth in 'digital' agricultural enterprises, without properly considering the structure of the agro-industrial complex, its levels from international to personal subsidiary plots, the different nature of its institutions, commercial and non-commercial one, and its social component [11].

If we summarize the current difficulties of the functioning and development of the Russian society and state in the international field, in particular, this concerns military-diplomatic relations, the sanctions and countersanctions, then, obviously, there is a distraction from digitalization of significant funds for maintaining the national security of the country, strengthening and maintaining its defense capability, to overcome the negative phenomena caused by the collapse of the USSR, the well-known rupture of economic ties between its former union republics, with the formation of a full-fledged mixed economy in Russia, and with the need for the wellbeing of its population, the speedy elimination of unjustified and unfair social stratification [12].

A significant share of efforts to digitize the agro-industrial complex in Russia, although with the active and productive participation of the federal center (like science, personnel, technology, financing, and international exchange) now falls on the agro-industrial complex itself, on its capabilities, on the capabilities of its commercial and non-profit organizations. [14]. It must be said that today its role in this process is constrained by the following circumstances:

- the 'freshness', scale, specificity, and cyclicity of its certain structures (for example, take at least the 'chipping' of millions of heads of cattle, pigs, sheep, goats, etc.; or monitoring the agrotechnical state of fields);

- the participation inconsistency in various forms of ownership, a variety of organizational and legal formations, levels, monopolism, etc.;

- the lack of synchronization, consistency, and comprehensiveness of the approach to digitalization, especially in connection with the existence of various technological structures, including the sixth, in the country's agroindustrial complex;

- the formation of a new economy based on knowledge and technologies, accompanied by a scientifically grounded use of modern digital technologies and artificial intelligence [4];

- the inconsistency of interests of various actors in the field of the agro-industrial complex, the IT sector and other entities 'tied' to its digitalization (both explicit and latent; both legitimate and extralegal);

- differences in access to modern information technologies, including dual-use ones, by various actors of the society and state due to financial, personnel, material, and technical, technological, legal (in particular, intellectual property rights), both internal and external differences;

- the need to ensure the congruence and interconnection of both types of information technologies (like clouds, hardware, geolocation, radio frequency identifiers, automated production and management systems, and guidance), and the latter with basic production, management, other technical and technological, economic, ecological and social systems;

- asymmetry and digital inequality of various economic entities at the international, national, and other levels of localization;

- acute competitive, both national and international competition in the field of digitalization;

- the importance of integrating science, production, service, logistics, etc. in the field of digitalization, differentiated by trophic, food, and other cooperative chains to increase the safety, level, and quality of 
consumption of agricultural products, both in raw and processed form; finding with the help of artificial intelligence the optimal forms, types, the scale of activities of economic entities in the field of the agro-industrial complex, its rational specialization, and cooperation, including in related industries;

- the need for rational, high-quality formation, development, and culture of using digital technologies, upbringing, education, training, professional training, and retraining of labor resources [15];

- humanization of the digital technosphere (in particular, it concerns the provision of effective employment, unemployment, etc.);

- information and communication technologies decriminalization both in the agro-industrial complex and in other spheres of society at all levels;

- protection of civil rights and freedoms of villagers in the field of digitalization and use of artificial intelligence.

\section{Conclusion}

There is no doubt that the intensification of the introduction and use of digital and information technologies in the agro-industrial complex of the Russian national economy in modern conditions will not only significantly increase its efficiency, more fully and more deeply satisfy the growing needs of both Russians for food, and industry for agricultural raw materials, consumers and buyers abroad, taking into account both the general growth of the world population (according to projected estimates, it will reach 10 billion people by 2050, and the number of hungry, malnourished, sick due to incomplete, unbalanced nutrition, social inequality of consumption, especially high-quality economic benefits that agriculture initially creates, i.e. the poor, all those who are deprived of real/timely access to them [13]. The speed and efficiency of solving these global problems depends not only on Russia, but also on its synchronized, productive, congruent cooperation in this respect with other countries, both developed and developing, both with the center and with semi-periphery and periphery.

\section{References}

Aaltonen, A. and S. Seiler (2016). Cumulative growth in user-generated content production: Evidence from Wikipedia. Management Science 62(7), 2054-2069.

Farm Beats: AI \& Io $\mathrm{T}$ for Agriculture Established: May 14, 2015 [Electronic resource]. - URL: https://www.microsoft.com/en-us/research/project/farmbeats-iot-agriculture (access date: 10.12.2020).

Guerra M. 3 Ways the IoT Revolutionizes Farming, 2017 // Electronic Design [Electronic resource]. - URL: http://www.electronicdesign.com/analog/3 -ways- iot-revolutionizes-farming (access date: 22.06.2020).

Is Artificial Intelligence Agriculture the Way of the Future? // Synthetic Smarts (Apr 30, 2018) [Electronic resource]. - URL: http://syntheticsmarts.com/artificial-intelligence-agriculture/ (access date: 29.06.2020)

Prahalad C. K., Hamal G. The core competence of the corporation // Harvard Business Review. 1990. Vol. 69. N. 3. PP. 79-97.

Alekseenko O.A., Ilyin I.V. Digitalization of the global world and the role of the state in the global economy // Information Society. 2018. No. 2. PP. 25.

Aitpaeva A.A. Digitization of agriculture in the context of increasing the competitiveness of the domestic agroindustrial complex // Bulletin of the Astrakhan State Technical University. Series: Economics. 2019. No. 3. PP. 56-63.

Volostnov, N.S., Lazutina, A.L., Smirnova, Z.V., Batsyna, Y.V., Statuev, A.A. Model of integration of social and economic processes as factor of effective management of municipal structures // International Journal of Management, 2020, 11(5), PP. 797-802

Kapranova L.D. Digital economy in Russia: state and development prospects // Economy. Taxes. Right. 2018. No. 2. P. 58

Moskalev S.M., Klimenok-Kudinova N.V. Artificial intelligence and the Internet of things as innovative methods of improving the agro-industrial sector // Bulletin of the St. Petersburg State Agrarian University. - 2018 No. 3 (52). - PP. 121-130.

Nikitin A.V., Ognivtsev S. B. Development strategy of the innovative scientific and technological center of the agro-industrial complex // International agricultural journal. 2018. No. 3

Ognivtsev S. B. The concept of a digital platform of the agro-industrial complex // International agricultural journal. 2018. No. 2

Pichkov O.B. Ulanov A.A. risks and imperfections in the development of the digital economy at the present stage // Insurance business. 2017. No. 11. P.3

Skvortsov E.A., Skvortsova E.G., Sandu I.S., Iovlev G.A. The transition of agriculture to digital intelligent robotic technologies // Economy of the region. 2018. Issue 3. Vol. 14.P. 1017-1018.

A.A. Strokov Digitalization of education: problems and prospects // Bulletin of the Minin University. 2020. Vol.8. \#2. 
Chibisova I.S. Application of information technologies in agriculture in Russia. Age of Science № 13. 2018. P. 92 